\title{
Description of Strains of Peptostreptococcus anaerobius Isolated from Subcutaneous Abscesses in Cats
}

\author{
By DARIA N. LOVE, R. F. JONES AND MARILYN BAILEY \\ Department of Veterinary Pathology, University of Sydney, \\ N.S.W. 2006, Australia
}

(Received 12 December 1978)

\begin{abstract}
Strains of Peptostreptococcus, Streptococcus and of a Gram-positive coccus, which was initially isolated as an anaerobe but grew subsequently as a facultative organism, were isolated from subcutaneous abscesses in cats. The cat strains of Peptostreptococcus gave metabolic fermentation products in combinations described for $P$. anaerobius. The Streptococcus strains conformed to the group $S$. intermedius. The facultative organism described had the metabolic products of $P$. anaerobius but the distinctly different biochemical characteristics of $S$. intermedius and fits neither of the genera strictly.
\end{abstract}

\section{INTRODUCTION}

Controversy surrounds the classification of some of the Gram-positive anaerobic cocci (Rogosa, 1974; Sutter et al., 1975). Rogosa (1974) suggests that the organisms which were formerly classified as Peptostreptococcus intermedius but which are not strict anaerobes, i.e. they will grow on the surface of agar plates after several subcultures, should be removed from the genus Peptostreptococcus and placed in the genus Streptococcus. This view is held by others who now classify this organism as Streptococcus intermedius (Holdeman et al., 1977; Sutter et al., 1975) as it is primarily saccharoclastic with lactic acid as the sole major product of fermentation. We have isolated and characterized another facultative Grampositive coccus which does not appear to fall strictly into any of the genera so far described.

\section{METHODS}

Ten strains of Peptostreptococcus, four strains of Streptococcus and three strains of a Gram-positive coccus, which was initially isolated as an anaerobe on supplemented brain heart infusion agar (Holdeman \& Moore, 1975) but grew subsequently as a facultative organism, were isolated from subcutaneous abscesses in cats. The reference strain ATCC 27337 of Peptostreptococcus anaerobius was included for comparison. Pure cultures of each strain were grown anaerobically in peptone/yeast extract/glucose (PYG) medium (Holdeman \& Moore, 1975) and in cooked meat plus BVF-OS broth (Turner et al., 1935) supplemented with 0.4\% $(\mathrm{w} / \mathrm{v})$ glucose, $0 \cdot 1 \%(\mathrm{w} / \mathrm{v})$ cellobiose, $0 \cdot 1 \%(\mathrm{w} / \mathrm{v})$ maltose and $0 \cdot 1 \%(\mathrm{w} / \mathrm{v})$ starch (CMC medium). Facultative organisms were also grown aerobically in CMC and PYG (not pre-reduced) media and their metabolic products were analysed. Selected strains of each group were tested for their fermentation products from peptone/yeast extract/threonine (PY-T) and peptone/yeast extract/pyruvate (PY-P) media (Holdeman et al., 1977). All metabolic products were extracted according to the procedures of Holdeman \& Moore (1975) and analysed by gas-liquid chromatography (g.l.c.) using a Hewlett-Packard gas chromatograph (model $5830 \mathrm{~A})$ fitted with a glass column $(160 \mathrm{~cm} \times 2 \mathrm{~mm}$ i.d.) packed with either $10 \%(\mathrm{w} / \mathrm{w})$ AT1200 (Alltech Associates, Illinois, U.S.A.) plus $1 \%(\mathrm{w} / \mathrm{w}) \mathrm{H}_{3} \mathrm{PO}_{4}$ on Chromosorb (Johns-Manville Inter Corp., Colorado, U.S.A.) W-AW, 80/100 mesh, which was used for routine analyses, or 5\% (w/w) FFAP (Deltron, Summer Hill, N.S.W., Australia) on Chromosorb W-HP, 80/100 mesh. The carrier gas (nitrogen) flow rate was $30 \mathrm{ml} \mathrm{min}-1$, the oven temperature was $115^{\circ} \mathrm{C}$, and the flame ionization detector was at $225^{\circ} \mathrm{C}$. The machine was computer programmed to quantify the products of fermentation against standards of 1 mequiv./100 ml values. 
The biochemical tests performed were those described for the anaerobic cocci by Holdeman et al. (1977). Peptone/yeast extract/sugars were pre-reduced (Holdeman et al., 1977) while other biochemical tests were incubated anaerobically in the BBL GasPak Anaerobic System in which the catalysts had been rejuvenated by heating before each use (Holdeman et al., 1977).

\section{RESULTS AND DISCUSSION}

The strains of strictly anaerobic Gram-positive cocci isolated from cats, as well as the reference strain of $P$. anaerobius, were similar in cultural characteristics. They were inactive biochemically, i.e. they did not ferment a wide range of sugars, did not hydrolyse aesculin and did not react in the range of other tests described by Holdeman et al. (1977). In both PYG and CMC media, incubated anaerobically, $P$. anaerobius ATCC 27337 produced acetic and isobutyric acids $(>1$ mequiv. $/ 100 \mathrm{ml})$ and butyric acid $(<1$ mequiv. $/ 100 \mathrm{ml})$. The cat strains of $P$. anaerobius produced acetic, isovaleric and isocaproic acids $(>1 \mathrm{~m}$ equiv. $/ 100 \mathrm{ml}$ ) and propionic, isobutyric, butyric and valeric acids $(<1$ mequiv. $/ 100 \mathrm{ml})$. From pyruvate they produced acetic, isobutyric, isovaleric and isocaproic acids $(<1 \mathrm{~m}$ equiv. $/ 100 \mathrm{ml}$ ), and threonine was converted to propionic acid. Strains of $S$. intermedius produced acetic acid $(<1$ mequiv. $/ 100 \mathrm{ml}$ ) and lactic acid $(>1$ mequiv. $/ 100 \mathrm{ml}$ ) when grown both aerobically and anaerobically, produced acetic and lactic acids from pyruvate but did not convert threonine to propionic acid. They had the biochemical and morphological characteristics described for $S$. intermedius (Holdeman et al., 1977), including hydrolysis of aesculin and acid formation from a wide range of sugars.

The third group of Gram-positive cocci were isolated as anaerobes but, after several subcultures, grew well aerobically. These strains had morphological and biochemical characteristics similar to $S$. intermedius, i.e. they produced acid from glucose, lactose, maltose, sucrose and cellobiose and hydrolysed aesculin. However, their metabolic fermentation products were similar to those of the cat strains of $P$. anaerobius. These products were formed in PYG, CMC and PY-P media incubated both aerobically and anaerobically, although in all strains the amounts of each product were greatest in CMC medium. Threonine was converted to propionic acid.

A feature of $P$. anaerobius and the uncharacterized organism, but not of streptococci, was the production of very large amounts of isocaproic acid. This acid was detected as its methylated derivative by g.l.c. on AT1200 (but not FFAP) columns, and its identity was confirmed by g.l.c.-mass spectrometry. It was produced in cultures of cat strains and the reference strain of $P$. anaerobius grown anaerobically in PYG and CMC media and by the facultative organism under both anaerobic and aerobic conditions in $\mathrm{CMC}$ and P.YG media.

The metabolic products of the cat strains of $P$. anaerobius were diverse but were present in combinations described for the genus (Rogosa, 1974). The strains which remained anaerobic despite continued subculture are true members of the genus Peptostreptococcus. Streptococcus, on the other hand, is a facultative organism and its major fermentation product is lactic acid (Deibel \& Seeley, 1974). It seems correct, therefore, to group $S$. intermedius according to its lactic acid production despite its reluctance to grow aerobically until multiple subculturing has taken place. The facultative organisms described here have the metabolic products of $P$. anaerobius but the distinctly different biochemical characteristics of $S$. intermedius. It is also clear that these facultative organisms fit neither of these genera strictly. If the emphasis is to be placed on metabolic fermentation products rather than growth requirements and biochemical tests, they should be grouped with the peptostreptococci and may be 'aerotolerant strains' of $P$. anaerobius with different biochemical reactions. As with $P$. anaerobius, isocaproic acid is a major metabolite. If, however, the genus contains only strict anaerobes they must be placed elsewhere. 
We wish to thank Mrs A. M. Whittington for preparation of media. This work was supported by a Sydney University Research Grant.

\section{REFERENCES}

Deibel, R. H. \& Seeley, H.W. (1974). Genus I. Bergey's Manual of Determinative Bacteriology, Streptococcus. In Bergey's Manual of Determinative Bacteriology, 8th edn, p. 490 . Edited by R. E. Buchanan \& N. E. Gibbons. Baltimore: Williams \& Wilkins.

Holdeman, L. V. \& MoORE, W. E. C. (1975). Anaerobe Laboratory Manual, 3rd edn. Blacksburg, Va: Virginia Polytechnic Institute and State University.

8th edn. Edited by R. E. Buchanan \& N.E. Gibbons. Baltimore: Williams \& Wilkins.

SUUtTer, V. L., VARGo, V. L. \& Finegold, S. M. (1975). Wadsworth Anaerobic Bacteriology Manual, 2nd edn. Los Angeles: Department of Continuing Education in Health Sciences, University Extension and the School of Medicine, University of California.

Holdeman, L. V., Cato, E. P. \& Moore, W. E. C. (1977). Anaerobe Laboratory Manual, 4th edn. Blacksburg, Va: Virginia Polytechnic Institute and State University.

Rogosa, M. (1974). Genus II. Peptostreptococcus. In

Turner, A. W., Campbell, A. D. \& Dick, A. T. (1935). Recent work on pleuro-pneumonia contagiosa bovum in North Queensland. Australian Veterinary Journal 11, 63-70. 